\title{
Kante zeigen
}

Liebe Leserin, lieber Leser,

auf die Gefahr hin, mich unbeliebt zu machen, steige ich hier in die Debatte um ein Tempolimit ein. Das Dilemma einer Argumentation bei Tempo 130 ist ja ähnlich wie beim Rauchen: Dagegen kann man eigentlich nicht sein, weil die oberen $50 \%$ des Geschwindigkeitsbereichs bis $250 \mathrm{~km} / \mathrm{h}$ der Umwelt vom Energieeinsatz her mehr schaden und wenn's schiefgeht tendenziell erheblich mehr Gesundheitsrisiken für sich und andere bergen als die unteren $50 \%$. Dafür sein kann man schon, diese Position ist moralisch deutlich einfacher zu vertreten. Kleines wirtschaftliches Zusatzargument: Der Schilderwald würde sich etwas reduzieren, und man müsste sich weniger genau merken, was gerade gilt - fährt man in einer Zone 100 aus Versehen 130, hat man ein wesentlich geringeres Problem als mit $250 \mathrm{~km} / \mathrm{h}$.

Da ich stark vermute, dass es uns mangels messbarer Gegenargumente ohnehin irgendwann bevorsteht, mit Tempo 130 über die Autobahn zu gleiten, kann man das Thema auch gleich proaktiv gestaltend aufgreifen: Denkt man die Geschichte weiter, lassen sich für flächendeckende Tempolimits bestimmte Themen im Rahmen der Automobilentwicklung sinnvoll aufgreifen. Beispielsweise habe ich Geofencing seit dem spannenden PHEV-Fokus von Gernot Goppelt in ATZelektronik 7-8 als neues Thema für mich entdeckt. Geofencing dient im Beitrag Nutzen stiftend der Umschaltung von Hybridfahrzeugen in den Elektromodus, wenn sie in eine Umweltzone einfahren. Eine sinnvolle Option, um den Anteil der elektrisch gefahrenen Zyklen eines Fahrzeugs zu erhöhen. Denkt man die Technik weiter, lässt sie sich auch verwenden, um Fahrzeuge automatisch auf eine bestimmte Geschwindigkeit zu beschränken. Reflektiert man das Thema emotionslos, eröffnen sich daraus durchaus Vorteile: Überall geltende feste Maximalgeschwindigkeiten, unterstützt durch Geofencing, dürften mittel- und langfristig die Automatisierung von Fahrzeugen erleichtern, da die Sensorik ebenso wie Software und Rechner weniger performant sein müssen als bei hohem Tempo; als Nebeneffekt sinken Lärm- und Umweltbelastung sowie Stresslevel. Zudem kann ein fertiges System, das als Lizenz oder von der Stange mit einem validierten Sensorsetup sowie Rechner- und KIArchitektur automatisiertes Fahren bis Tempo 130 ermöglicht, ein Geschäftsmodell sein, wenn man nicht unbedingt High-End-Fahrzeuge, sondern High-End-Mobilität verkaufen möchte.

Ein technisch durchgesetztes Tempolimit mag für ambitionierte Fahrer ein Graus sein, bringt aber letztlich nur eine persönliche Vorliebe in Einklang mit der Rechtslage auf öffentlichen Straßen. Wer das nicht mag, darf das sagen. Allerdings gilt am Ende dennoch der Kant'sche Ansatz, dass die Freiheit des Einzelnen dort endet, wo die Freiheit des Anderen und somit auch die der Allgemeinheit beginnt.

Viel Spaß bei der Lektüre des Hefts.

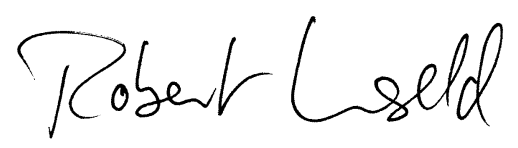

Robert Unseld

Verantwortlicher Redakteur

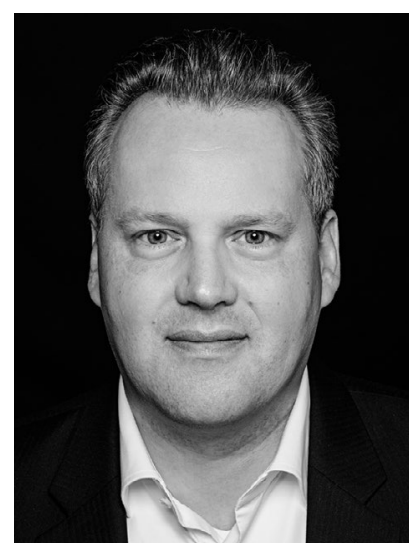

Für eine sichere automatisierte Zukunft.

Von Fahrerassistenzsystemen bis hin zu hochautomatisiertem und autonomem Fahren mit zunehmender Automatisierung steigt die Komplexität im Fahrzeug und fordert neue Entwicklungs- und Validierungsansätze. Mit unserem durchgängigen und modellbasierten Systems Engineering helfen wir Ihnen komplexe Herausforderungen frühzeitig anzugehen und bringen gemeinsam Ihre Innovation sicher auf die Straße.

ITK Engineering GmbH -

Ihr Partner für automatisierte Mobilitätslösungen von morgen.

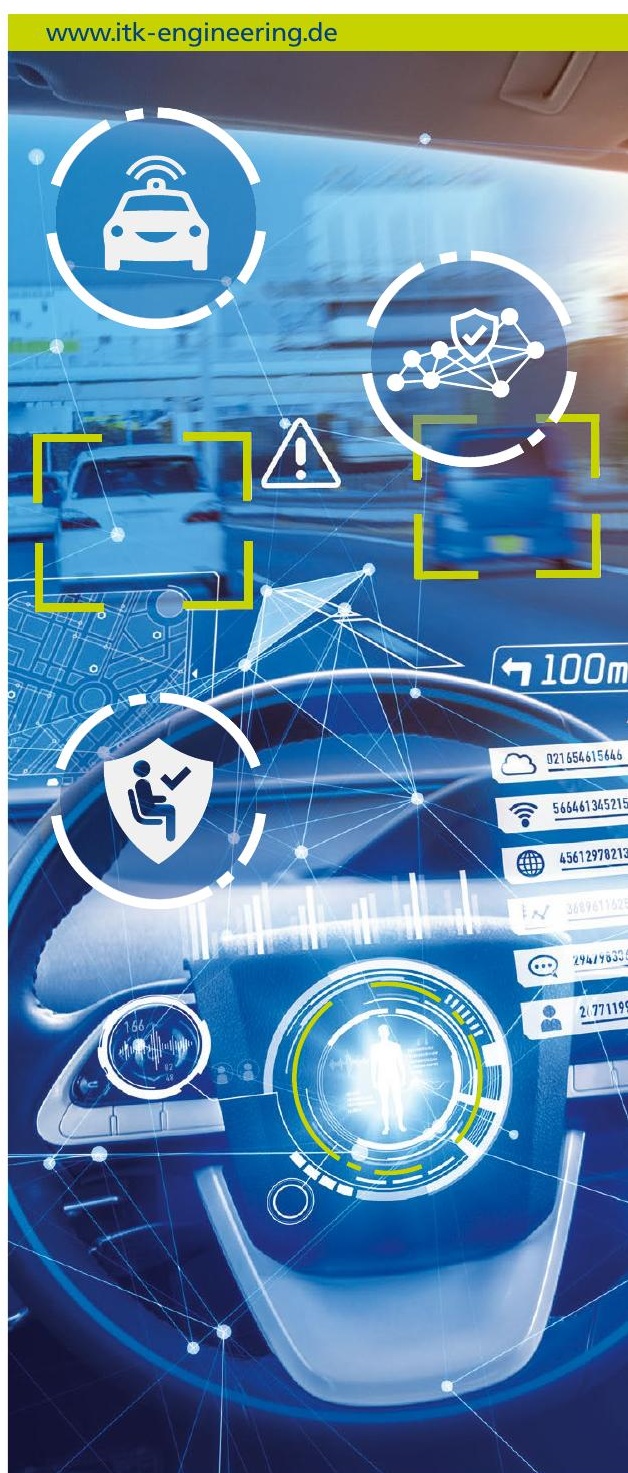

